\title{
Building a Partnership to \\ Address Violence in Three \\ Historically Colonised Contexts: \\ Report on Research Meeting in \\ Memphis
}

\author{
Sandy Lazarus \\ Medical Research Council/University of South Africa \\ Crime, Violence and Injury Lead Programme \\ slazarus@uwc.ac.za
}

\section{Teresa Cutts}

Methodist LeBonheur Healthcare, Memphis;

African Religious Health Assets Programme,

Memphis/South Africa

cuttst@methodisthealth.org

\section{INTRODUCTION}

This report provides an overview of a research visit and planning meeting held at the Methodist LeBonheur Healthcare (MLBH) in Memphis, Tennessee, United States of America (US) in December 2008. The purpose of this meeting was for the invited participants to plan a longitudinal study around the working title: 'Understanding the positive mediating influences of faith, religion and spirituality on self-inflicted and interpersonal violence involving males in contexts of historical trauma: An inter- and intra-city comparison in South Africa and United States of America'.

The meeting was hosted by Dr Gary Gunderson and Dr Teresa Cutts of the MLBH, who are also key researchers in the African Religious Health Assets Programme (ARHAP). Cutts and Professor Sandy Lazarus (Medical Research Council-University of South Africa (MRC-UNISA) Crime, Violence and Injury Lead Programme (CVILP)) facilitated and recorded the process. The other participants in the meeting were Prof. Jim Cochrane of ARHAP, South Africa (University of Cape Town), and local partners from Memphis, Pastor Dianne 
Young (The Emotional Fitness Centre/Healing Centre, Memphis), Bishop William Young (The Emotional Fitness Centre/Healing Centre, Memphis), Dr Leon Caldwell (Rhodes College/Centre for the Advancement of Youth Development, Memphis), and Dr Kitty Lawson (Victims to Victory, Memphis). Other key international partners in the project who were not able to be present at the meeting, but contributed to its planning and follow-up processes, were Prof. Mohamed Seedat (Institute of Social and Health Sciences, MRC-UNISA CVILP), and Dr Bonnie Duran (Indigenous Wellness Research Institute, University of Washington, Seattle).

The first section of this report provides a summary of the study that constituted a focus for the meeting. This is followed by a brief report on key events and experiences during the visit from 9 to15 December 2008. The outcomes of the meeting with partners are captured in a developing research proposal which, when finalised in 2009, will be used for grant applications and further research purposes.

\section{The Study}

The overall aim of the study that constituted a focus for the meeting was to understand the positive mediating influences of faith, religion and spirituality on self-inflicted and interpersonal violence involving males in contexts of historical trauma in specific cities in South Africa and the US - for the purposes of developing safe and peaceful communities. Specific research objectives include:

- To obtain a picture of the rates and nature of violence in the cities and communities that constitute a focus for this study - generally, and in relation to males more specifically

- Toconduct a critical analysis of these data for the purposes of understanding the main determinants of violence, especially in relation to males, in these contexts

- To illuminate the relationship between faith/religion/spirituality and violence, within the context of health promotion, with a particular focus on religious health assets - and to develop a conceptual framework that can help to guide and achieve the aims of this research

- To operationalise these religious health assets in a way that honours local knowledge and healthworlds, and that allows for a valid and trustworthy research process 
- To identify and understand existing religious health assets in the research sites - the positive mediating influences of faith/religion/spirituality, particularly at population scale (not primarily individual), on self-inflicted and interpersonal violence involving males

- To identify and understand the distinctive indicators that mark those assets that do facilitate or could facilitate systemic, contextually relevant and effective peace and safety promotion interventions

- To look more specifically at how these positive mediating influences can be used to promote positive, constructive masculinity, with a particular emphasis on fatherhood and father figures

- To pursue any further findings emerging from the research process - for the purposes of answering key research questions

- To develop recommendations for safety and peace promotion programmes on the basis of the findings of this study

- To analyse, write up and transparently share the findings of this research with local role players for the purposes of identifying strategies that could be pursued to develop safe and peaceful communities, with a particular focus on promoting generative masculinity and fatherhood

- To disseminate, in appropriate ways, the findings of the research with key local, national and global role players, including relevant government stakeholders

- To do all of the above within a community-based participatory research (CBPR) framework.

Although the development of an appropriate conceptual framework that links the relevant variables in a coherent framework relevant to this particular study needs to be developed as part of this study, the CVILP's developing responsive critical public health $(\mathrm{RCPH})$ framework will be used as a starting point. In summary, this developing $\mathrm{RCPH}$ framework includes the following characteristics. First, the framing of the study needs to be sensitive to and transformed by local, community-embedded voices and knowledge. Second, it will draw on a particular social theoretical lens characterised by: historical and contextual analyses; focusing on political and economic relations; emphasising power relations, particularly within racial and gender social relations; focusing on structural and relational identity (including masculinity); seeking to address oppression of various kinds; considering the effects of history, and of inter-generational colonial and apartheid trauma; utilising strategies to uncover alienation through deconstruction of ideologies; supporting processes of empowerment and transformation, with participation and collaboration 
being key values and actions; contributing to social action and social justice; and taking marginalised indigenous and local knowledge seriously. All of the above highlight the fact that power dynamics constitute a central aspect of this approach and lens. Third, the public health approach includes relevant aspects of the prevention and health promotion approaches, including research and intervention that includes the following aspects or steps: defining the problem and identifying the risks and causes of violence, identifying the health determinants and causes of life, through to developing and evaluating interventions aimed at developing safe and peaceful communities. A systems or ecological approach is also usually part of this framework, with an emphasis on the need to identify factors and their interplay at the individual, relationship, community and societal levels of the system.

The research methodology to be employed will include both qualitative and quantitative methods of enquiry, pursued within the public health's violence prevention and safety and peace promotion frameworks (including epidemiological and intervention approaches), and a critical analysis (drawing on critical social theories). The research methodology will be located within a CBPR framework, which is congruent with the RCPH framework referred to above. The research will, therefore, inform community development interventions aimed at violence prevention and peace and safety promotion in the research sites: (a) Johannesburg and Cape Town in South Africa; (b) Memphis in the US; and (c) Native/Indian American communities identified by the Indigenous Wellness Research Institute in Seattle, US. A common contextual thread than 'runs through' these communities and sites is the historical colonisation experienced by South Africans (under apartheid particularly), African Americans (who make up the majority of Memphis' population), and Native/Indian Americans (through the Indigenous Wellness Research Institute).

\section{Key Events and Experiences During the Research Visit}

\section{Visits in the community}

The first days of the visit comprised various meetings with local leaders inside and outside of the MLBH. Because of Gunderson's own position as Senior Vice-President of the organisation (which is a very large healthcare system, including seven hospitals, with an annual $\$ 1.5$ billion budget), the South African partners were able to meet various leaders in the system, including the 
Chief Executive Officer of the hospital system. A tour of the hospital system included being shown plans for the building of the Centre of Excellence in Faith and Health which will shortly be built as part of the MLBH's main hospital.

In addition to meeting key personnel in the MLBH on the first day, the core researchers spent some time with Dr Scott Morris of the Church Health Centre. $\mathrm{He}$ is a key person in Memphis (and nationally) in bringing faith and health together. This was followed by a visit to the Hope and Healing Centre where the holistic approach to wellness was revealed. This is a wellness centre aimed at those who cannot afford the more expensive wellness programme options. The Hope and Healing Centre offers a variety of holistic and integrated healing interventions, with spiritual values and religious traditions being centrally located in all aspects of the work. Besides the personal and interpersonal values guiding the work at the centre, the architecture of the building (specially built for its purpose) is health promoting in itself.

On the afternoon of the second day the team attended a pivotal meeting at the MLBH. This meeting included 100 religious leaders who are part of the Congregational Health Network being developed under Gunderson's leadership. The network and advocacy meeting was called for the purpose of engaging with the health insurance crisis in Memphis (which is the poverty capital of the US), focusing particularly on those who are un-insured or underinsured and therefore excluded from or marginalised within the healthcare system. The discussions at this event focused on political action for universal health coverage in the US, and, at the local level, partnerships between the health and faith systems. The latter is the key focus of Gunderson's work - and the context within which our research project will be taking place. Although it is currently predominantly Christian in membership, the religious minorities in the city are starting to enter the process. Some of the key people from this network were part of the succeeding research planning meeting.

\section{Understanding the PIRHANA method}

In addition to the above mentioned meetings and exposure, some time was spent going through the ARHAP documents, with a particular focus on the Participatory Inquiry into Religious Health Assets, Networks and Agency (PIRHANA) tool and methodology (De Gruchy, Matimelo, Jones, Molapo, \& Germond, 2005). This model has been used for religious health assets mapping in South Africa, Zambia, Lesotho, and other African countries, and in Memphis 
(across five under-served neighbourhoods). This approach honours, articulates, and "calls out" specific religious health assets of both a tangible nature (e.g. church buildings, health ministries, leaders who hold both faith and health leadership roles) and an intangible nature (e.g. blessings, relational ties to other programmes and organizations). ARHAP is interested in what contributes to health and healing as is understood in the more holistic African context, involving comprehensive well-being of the community, body, mind and spirit.

PIRHANA recognises that a significant asset of religion is the networks and relationships that it fosters (assets which are sometimes termed "social capital"). Additionally, the inquiry is based upon the framework that people are "actors" in the field of both religion and health and that their faith impacts them as they engage in both health-seeking and health-providing behaviour (agency). The approach is grounded upon appreciative inquiry, so seeks to be empowering rather than extractive. Local members of the communities that are mapped drive the inquiry and have ownership of the work and findings.

By focusing on the strengths of communities, those communities' collective ability to prevent illness is enhanced, helping individuals to self-manage chronic conditions and enhance overall health on a community level. PIRHANA builds on the foundation of what communities actually have, rather than focusing on things that they may not have. The assets of faith groups are distinctive in that they may appear to be intangible, yet they produce highly tangible relationships, connections, values, trusted stories and powerful rituals that make it possible for the whole strength of communities to rise to the challenges and threats they may face. Leaders at all levels of faith groups can be engaged as allies in healthcare and public health initiatives to build healthy, responsive communities. These processes capture more creative, yet realistic ideas about leveraging religious health assets from both healthcare and faith community partners.

The World Health Organization (WHO) funded early religious health assets mapping in Africa and has offered a resounding endorsement of ARHAP's work in Memphis. Reverend Canon Ted Karpf, the Partnerships Officer in the Office of the Director General of the WHO, has said: "The fact that the process will be replicated in Memphis gives the World Health Organization a chance to validate the techniques in a different culture, which is important to adapting the methods in many other parts of the world" (Associated Press, 2007). 
Some time was spent on going through the reports on the PIRHANA methodology recently employed in Memphis communities (ARHAP website: www.arhap@humanities.uct.ac.za; De Gruchy et al., 2005; Oliver, Graham, \& Schmid, 2006; Thomas, Schmid, Gwele, Ngubo, \& Cochrane, 2006). This included reading the manual that guides the research procedure and some of the reports on completed projects. The latter reports were very useful as they revealed concretely how this approach has been and could be used. Examination of these documents also revealed the promise of this methodology for the study focusing on identifying the positive mediating influences of faith, religion and spirituality on self-inflicted and interpersonal violence involving males in contexts of historical trauma. This methodology is grounded in a community-based participatory approach to research and development, and has the potential to be developed into a valid and trustworthy qualitative and quantitative data collection tool that honours the strengths of biomedical and more holistic approaches to health promotion.

Finally, a key highlight for the South African partners was an exposure to Memphis through "cultural immersion". In addition to being exposed to various forms of fried food (e.g. fried green tomatoes and fried corn bread), they were introduced to some Kings of Memphis, including: (a) a visit to the King of Rock, Elvis Presley's, Graceland home; (b) a night at BB King's Blues Bar for some excellent jazz; and (c) a visit to the place where Dr Martin Luther King was assassinated - a visit that held particular meaning given the impact of his life and death on many South Africans involved in the struggle against apartheid during the 1960s-1990s. It was also important to get a "feel" for this event because of its central significance in the lives of the majority African American population of Memphis. Many in Memphis also recognise and honour their religious "King". Memphis is a "faith-saturated", predominantly Christian city that has approximately 3000 faith communities within a metropolitan statistical area with a population of roughly 1.2 million people. This makes it a key site for an exploration of faith and spirituality as it relates to violence prevention and peace promotion.

\section{Research planning meeting with research partners}

The two-day research planning meeting followed the initial community visits and cultural immersion. These discussions provided a broad background for the more specific research proposal development which constituted a focus only at the end of the second day's conversations. It provided an opportunity for 
all present to talk about their interests and passions relating to the research project, as well as to share ideas of how the research should be focused so that it meets local (in this case, Memphis) needs.

The meeting commenced with an overview of the purpose of the meeting, and the research project envisaged. Each partner then spent some time sharing relevant background information, and providing some details relating to relevant institutional, research or community development backgrounds particularly insofar as they relate to violence, and peace and safety promotion. The focus was primarily on learning about the work of local partners, in particular: (a) the work of Dr Kitty Lawson at Victims to Victory; (b) Dr Leon Caldwell's work at the Centre for the Advancement of Youth Development; and (c) the work of Bishop William Young and Pastor Dianne young at the Healing Centre, the Emotional Fitness Centre, and their early morning radio programme in Memphis.

The group explored how faith-based groups impact violence prevention locally. There was also some discussion of the historical trauma experienced as a result of colonisation experienced by African Americans in the US, and how this has played itself out in the Memphis context. The pain and shame resulting from the assassination of Luther King in Memphis was particularly noted. An interesting discussion on the impact of the election of President Obama - particularly for African Americans in the US - also ensued. Finally, there was a great deal of discussion around the importance of focusing on males and masculinity in the context of violence, and violence prevention and peace and safety promotion. There was general agreement that this research project should include a particular focus on males and masculinity/masculine identity, with a specific emphasis on the role of fatherhood and father figures as potential protective factors.

From a research standpoint, strong support was lent to a focus on strengths (particularly strengths relating to networks), on what works, and on identifying and building on those assets. Members of the research team offered recommendations to inform the research focus, particularly narrowing that focus on male violence, fatherhood issues and looking at an age range of out-ofschool males, aged approximately 18-30.

The final day of the meeting focused on the development of the research proposal for this study, with a great deal of discussion revolving around the 
specific research focus, aims and objectives. The first draft of the proposal was then crafted by the team - immediately after the meeting, and then through email communication with all present and absent partners over the next couple of months.

\section{Conclusion}

The visit and the research planning meeting were both very useful in relation to the original purpose of pursuing initial planning for the project concerned. Despite the absence of some key research partners, as well as limited time and busy schedules, the participants were able to cover all key areas, and to pursue the development of the research proposal.

In addition to fulfilling the aims of sorting out some research-related matters, the meeting was extremely successful from the point of view of the South African members present who obtained some idea of the challenges (in relation to male violence) and resources (particularly relating to faith/religion/spirituality) that exist in Memphis. The visit and meeting also provided an opportunity for them to discover that they are "on the same page" in terms of their passion and commitment to the aims of this research, and in relation to their basic values and principles, reflected in a common view of and commitment to collaboration and community-based research.

\section{Acknowledgements}

The authors would like to conclude by expressing their gratitude to: (a) the MRC, and the CVILP more specifically, for sponsoring Prof. Lazarus' flight; (b) Dr Gary Gunderson for covering the accommodation and administrative costs, and for hosting the meeting and providing the necessary institutional support for the venture; and (c) the local Memphis research partners who contributed centrally to the further development of the project, and to helping the South Africans understand the challenges and promises of the Memphis communities in their struggle to address violence and build safe and peaceful communities. 


\section{References}

Associated Press. (2007). Global model to be replicated to improve health in Memphis. Press release from Methodist LeBonheur Healthcare to the Associated Press, 2 August.

DeGruchy, S., Matimelo, S., Jones, D., Molapo, S., \& Germond, P. (2005). PIRANHA: Participatory inquiry into religious health assets, networks and agency, practitioner's workbook. University of KwaZulu-Natal: ARHAP.

Oliver, J., Graham, L., \& Schmid, B. (2006). ARHAP literature review: Sub-Saharan Africa. University of Cape Town: ARHAP.

Thomas, L., Schmid, B., Gwele, M., Ngubo, R., \& Cochrane, J.R. (2006). Let us embrace: The role and significance of an integrated faith-based initiative for HIV and AIDS. University of Cape Town: ARHAP Research Report: Masangane Case Study. Eastern Cape, South Africa. 